\title{
9. Social Theatre in Italian Universities
}

\author{
Livia Cavaglieri and Alberto Pagliarino ${ }^{44}$ \\ doi.org/10.3280/oa-637-9
}

\section{Introduction}

Founded at the beginning of the $20^{\text {th }}$ century as a specific and autonomous academic discipline (Max Herrmann's Theaterwissenschaft), Theatre Studies appeared in Italian universities in the second half of the 1950s (at the Università Cattolica of Milan, Universities of Rome and Padua) and came to maturity in 1970 with the foundation in Bologna of the first degree course in DAMS (Art, Music, Performing Arts and Cinema) (Ferraresi, 2019). But the relationship between university and theatre dates back to much earlier.

Since the beginning, the theatre generated in universities various representative celebrative forms and goliardic parodic practices, but also constituted a central element of the educational process and a pedagogically organic and integrated tool for the teaching of literature, language and rhetoric. Thus it enriched academic life throughout Europe, not only as an intellectual learning process, but also an active scenic practice.

In the $20^{\text {th }}$ century, the relationship between theatre and university took an unprecedented variety of modulations. In Italy, in particular, this has contributed substantially to founding, defining and spreading the phenomenon of social theatre in all its forms. In the first part of this essay, we will analyse the active practices of university theatre, which have prefigured and stimulated the link between applied didactic and participatory research. This link will form the object of the third part, where the main focus will be:

the role played by some universities in the development of social theatre, not [only attempting a] theoretical reading of the phenomenon, but rather attempting to contribute to the definition of its method, practice and obviously its theory through a direct intervention into practices and training of operators (Innocenti Malini, 2016, p. 52).

44 This essay was conceived together by the authors; the writing was divided as follows: paragraphs 1-2 were written by Livia Cavaglieri, paragraph 3 by Alberto Pagliarino. 


\section{At the Roots of Social Theatre: Forms and Practices of Active Theatre in Universities}

The phrase "university theatre" gathers under a single category experiences born with different objectives and characterised by various articulations of the relationships between students, teachers, academic bodies and the outside world. University theatre can be many things, indeed: a spontaneous student practice or an activity stimulated by the teachers. It can be independent from the institution (even antagonistic to it) or strongly framed within it (even structured in a course of studies). It can play a professionalising function for students who wish to work in the field, but it can also be a disinterested experience of self-expression and self-awareness. It can be carried out by students, teachers, as well as by professionals and theatre-makers.

Veritable intermediaries between «academic and militant culture, theory and practice, theatre-literature and theatre-entertainment» (De Chiara, 1956), the university theatres born in Italy after World War II aimed at rediscovering and enhancing texts from the ancient and modern repertoire, through performances targeted at renewing the perspective on theatre and at freeing the theatricality of a dramaturgy suffocated by predominantly literary and philological studies. The issues of modern direction and the battle for resident companies were the pivots around which the thought of research and the practice of the stage were to be brought together. These early formations (Padua, Venice, Rome) built on the tradition of a university theatre well connected with the academic institution. On the other hand, the companies founded by students (at the universities of Genoa, Parma ${ }^{45}$, Milan Statale, Bari, Perugia, Palermo) prevailed from the mid-1950s, and were later welcomed and promoted by teachers from the area of Humanities. University theatre pre-dates the inclusion of theatrical studies in the academic curriculum and indeed had a driving role in affirming their dignity as a fullyfledged discipline. It contributed to the opening of the first chairs of History of Theatre and Performing Arts and to the promotion of the tangible, material nature of the scene to the rank of cultural issue ${ }^{46}$. Places of encounter, socialisation and maturation of personal identity for young privileged people, the university theatres of the first generation promoted values and behaviours which formed favourable ground for the taking root, in the following decades, of a conception of theatre centred on its use-value: the spirit of association (particularly present in the temporary festival communities),

${ }^{45}$ Since its foundation, this was a mixed group that brought together students, amateur actors and young workers.

46 The same role was fulfilled by university theatre in France; see Rollinat-Levasseur, 2019. 
voluntary work and the constitutive openness to the corporeal and experiential dimension of learning.

From the mid-1960s, university theatres underwent a radical overhaul of their content, structure and purpose and pursued the idea of «theatre and theatre practice as instruments of political communication and social action» (Gandolfi, 2015, p. 87). There was no more time for formal experiments and issues internal to the student body, as the time for class struggle had come. The reference to a more politicised horizon led to favouring the rediscovery of popular cultures and to incursions into geographical and human territories, until then considered marginal and subordinate. University theatres fully participated in the wider wave of expansion of theatre in Italian society. In some cities, actually, they were at the forefront, moving out of their contexts, becoming instruments of decentralisation and cultural animation, shifting the attention from the product to the creative process. They also relativised the aesthetic reasons for the scene and focused on the creation of recreational and expressive opportunities, with political and pedagogical aims. Finally, they dealt with the collective processes of structuring the identity of individuals, of recovering public spaces and of reactivating civil and political actions.

In their investigation of alternative forms of theatricality, the university scenes became a vehicle for the transmission of theatre anthropology, of the ideas of the New Theatre and of Animazione teatrale: this happened, for example, in Bari (Animazione teatrale actions in the schools of the old town; presence of Augusto Boal in 1976, see Di Santo, 2004) and in L'Aquila (where the intense Animazione teatrale activity in schools was prepared by meetings with Giuliano Scabia and Franco Passatore, see Farneti, 1994). Meanwhile at the DAMS degree of the University of Bologna, thanks to Scabia, Animazione teatrale had become a form of participatory teaching.

The application of theatre in political and social contexts led to disagreements and break-ups. During the 1970s, some groups left the universities and were re-founded as cooperatives of professionals or community-based theatres: from the CUT (Centro Universitario Teatrale, that is university theatre centre) in Parma seceded the Compagnia del Collettivo, today Teatro Due (Becchetti, 2003); the founding members of the university theatre of Perugia turned to professionalism and became the Gruppo di Sperimentazione e Azione Teatrale Fontemaggiore; in Palermo, the university association Teatro Libero became a professional group; the TADUA of L'Aquila founded the company L'Uovo; in Genoa, a CUT that had been in full activity until then, went into crisis and generated the Teatro della Tosse.

However, many new groups were founded and remained determined to 
express their political and social commitment without severing their ties with the university: in Padua the Teatro Popolare di Ricerca officially became a CUT in 1971; in Brescia the CUT La Stanza, born in 1973, aimed from the start at entering into a relationship with the entire social environment of the city, and was one of the first to start a section of social theatre (Bernardi, Innocenti Malini and Susa, 2016).

Since the beginning of the 1980 s, in the context of a profoundly changed university, it is mainly the professors - sometimes former members of a university theatre - who have been building theatre practice spaces for students (although there are many exceptions, especially during the Panther movement), incorporating active theatre activities into their research work and involving professionals and operators. This is the formula of the «théatre encadré» (Ertel, 2004), in which the design and organisational weight of the trainers becomes decisive, as shown by its two most famous examples: the Centro Teatro Ateneo (Rome La Sapienza, 1981-2015) and the Soffitta (1988-, DAMS Bologna).

In this specific outline, where the practical dimension and the historicaltheoretical research are intensely intertwined, the theorisation of social theatre inaugurates, at the end of the $1980 \mathrm{~s}$, a new and fertile chapter (Cavaglieri and Gandolfi, forthcoming), thanks to the leading experiences of the Cattolica of Milan, which will be better explained in the second part of the intervention, of Urbino (Aenigma, see Minoia, 2013) and of Ferrara (Centro Teatrale Universitario and Teatro Nucleo, then Balamós Teatro, see Gandolfi and Fuoco, 2018).

\section{The Birth of Social Theatre: Academy Meets Communities}

In the last fifty years, many scholars and researchers have opened up to the investigation of theatrical forms in non-professional places, with nonprofessionals, in social contexts or for educational purposes. They have originated a number of research schools. For the purpose of this paper in the next pages we will focus on the university experience linked to the birth and development of the social theatre methodology ${ }^{47}$, born from the fertile experience of Sisto Dalla Palma and his Milan school, which later expanded to Brescia, Pavia, Turin, Catania; we will mention briefly some of its spinoffs, independent but clearly connected with it.

${ }^{47}$ For example, the research group of Teatro sociale d'arte (for an explanation of the meaning of Teatro sociale d'arte see the Notes on Translations on p. 7) at La Sapienza University of Rome, headed by Guido Di Palma, remains outside this brief description and constitutes a parallel path of recognised value. Teatro sociale d'arte is a term coined by Andrea Porcheddu (2017). 
Social theatre was born and defined in the university context, thanks to Dalla Palma's research in the suburbs of Milan in the 1970s, that reached methodological maturity twenty years later. Dalla Palma was a professor at the Università Cattolica del Sacro Cuore and a disciple of Mario Apollonio, one of the co-founders of the Piccolo Teatro di Milano, the first resident theatre in Italy. Dalla Palma developed his master's theories and studies on the themes of theatre and the active participation of citiziens. The central intuition of Apollonio's work was that theatre is capable of nourishing the human being all the more when it is "acted" and not just "seen" (Dalla Palma, 1971). They shared the idea of a "bottom up" theatre. From this key nucleus comes the experience of the Centro di Ricerca per il Teatro (CRT) founded by Dalla Palma on the outskirts of Milan. The CRT became a cultural meeting place where all the great masters of the avant-garde theatre - Odin Teatret, Tadeusz Kantor, Jerzy Grotowski and many others - gathered and mixed, developing into a place of reflection on the themes of a widespread and participatory theatre. Those were the years immediately following the workers' and students' demonstrations, thus the CRT also looked with interest at the numerous experiences of Animazione teatrale, which took the theatre out of its traditional spaces, into political contexts - factories, universities - or into places where deep needs could easily be perceived, such as former asylums, prisons and schools (Bernardi and Carpani, forthcoming). During the first twenty years of the CRT's activity, the theatrical practices that would later constitute the roots of social theatre were analysed and implemented. The first research group formed around Dalla Palma, consisting of Fabio Antolini, Claudio Bernardi, Bernadette Majorana, Renata Molinari, Alessandro Pontremoli. In the 1990s the group grew to include Laura Cantarelli, Monica Dragone, Fabrizio Fiaschini, Giulia Innocenti Malini, Alessandra Rossi Ghiglione, Guglielmo Schininà. At the same time, working in collaboration with Bernardi, Dalla Palma created the three-year training course called Anabasi, 1994-1998, inspired by Apollonio's "bottegaworkshop" concept, based on synergies between the Università Cattolica del Sacro Cuore of Milan and the CRT. In this way new scholars and artists were formed who, in the following decades, would contribute to developing the approach of social theatre and to spreading it nationwide.

The first definition of social theatre to appear in writing was formulated by Bernardi:

social theatre is concerned with the expression, training and interaction of people, groups and communities through performative activities that include the different genres of theatre, play, feast, ritual, sport, dance and cultural events (Bernardi, 1998, p. 157). 
In the following years university research produced many publications to improve and expand the methodology (Bernardi, 2004; Pontremoli, 2005; Rossi Ghiglione and Pagliarino, 2007).

In Milan, from 2001 onwards Anabasi's "bottega-workshop" was developed into a post-graduate further education course - promoted by the Università Cattolica - which in 2019 reached its seventh edition. This path of research and action was and still is partly channelled within the wider framework of the CIT Centro di Cultura e Iniziativa Teatrale "Mario Apollonio" (Mario Apollonio Centre for Culture and Initiative in Theatre), founded by Annamaria Cascetta and directed since 2014 by Bernardi, with a section dedicated to social theatre. The "bottega-workshop" model is thus structurally brought inside the university context, where the training of students focuses on group management and makes use of field internships within projects carried out in contexts such as prisons, mental health institutions, care-homes for the elderly, among others (Bernardi and Carpani, forthcoming).

The experience of social theatre research, training and action gradually spread out from Milan to other cities in Lombardy. In Brescia, Innocenti Malini taught social theatre in the Sciences and Technologies of the Arts and Performing Arts (STARS, Scienze e Tecnologie delle Arti e dello Spettacolo, that is to say sciences and technologies of the arts and performance) degree course until 2011, while Bernardi and Carla Bino carried out projects on sacred and festive themes from 1995 onwards. At the University of Pavia initially Faculty of Modern Languages and Cultures and now Department of Humanistic Studies - Fiaschini continues the advanced training course launched by Dalla Palma in collaboration with the Fraschini Theatre of Pavia.

Social theatre became social community theatre at the University of Turin in 2003 thanks to the collaboration between Pontremoli, Rossi Ghiglione and Pagliarino. The research group was involved in the early 2000s in the strategic regeneration plan of the suburbs of Turin.

In this context, a research-action phase on theatre and community was launched, involving universities, local authorities and theatre companies to conduct cultural experimentation in the context of the Progetti Interdipartimentali Ambiente e Salute - social support plans. This experience brought the focus of cultural work on the active participation of citizens. As a consequence, the methodology was expanded by adding the concept of community empowerment to the founding core of social theatre, that is the concept of "working with the group". Community empowerment, in turn, is based on community dramaturgy (Rossi Ghiglione, 2013) and on the creation of social capital through cultural action with the locality and through the 
development of local networks (Pagliarino, 2011). Deriving from the Social and Community Theatre Master - the first Italian master course in the field, which run for four editions until 2011 -, the Social Community Theatre Centre (SCT) was founded in 2014, under Rossi Ghiglione's scientific supervision and direction ${ }^{48}$. It is an establishment of international relevance resulting from an agreement between the University of Turin, the centre for research and lifelong learning Corep (Centro per la Ricerca e l'Educazione Permanente) and the Associazione Teatro Popolare Europeo or European people's theatre association.

The Centre promotes research, training and implementation of national and international projects. In particular it is carrying out an extensive work of methodological dissemination and innovation taking advantage of calls for proposals by Creative Europe, Erasmus Plus and Interreg-Alcotra (Rossi Ghiglione, Fabris and Pagliarino, 2019). These initiatives involved, among others, the Odin Teatret, the National Theatre of Nice and twenty-three other partners and forty-six associated partners from sixteen European countries, and cooperate, on a world-wide scale, with the International Organization for Migration and several international cooperation agencies - among which CIFA ONLUS and the Italian Ministry of Foreign Affairs - in Libya, Ethiopia, South Sudan, Lebanon.

Since 2003 the Turin team has developed a considerable experience of theatre and health, directed and conceived by Rossi Ghiglione, which has now become a permanent research area of the SCT Centre on cultural welfare and the first structured and interdisciplinary experience of theatre and health at national level (Pagliarino, 2017).

Starting from field research in health promotion and healthy ageing conducted originally in an oncology ward (Rossi Ghiglione, 2011a), a network was created involving the School of Medicine of the University of Turin, the Dors (regional documentation centre for health promotion), the Aress (regional strategic agency for health and social affairs), the Regional Oncology Network, several RSAs (residential care homes for the elderly), ASLs (local health services) and hospitals.

Since 2006, the network has been creating art and health courses for patients and care givers in Italy and abroad and developing university training for students of health faculties, launching impact assessment processes for the training of care professionals (Pagliarino, 2018) and stimulating a national debate with the first Forum on Theatre, Health and Wellness in 2013.

Now based in Milan as well as Turin, the research groups are open to

48 The management team also includes Alberto Pagliarino, Maurizio Bertolini and Silvia Cerrone. http://www.socialcommunitytheatre.com/it/ 
interdisciplinary and interdepartmental projects and collaborations with courses in social theatre dedicated to students specialising in different disciplines: primary education sciences, educational sciences, professional education, medicine, psychology and nursing.

The collaboration between CIT and SCT Centre led to the creation in 2018 of the first National School of Social and Community Theatre based in both cities. Milan holds a course on running and planning social community theatre workshops, while Turin offers a course on social community theatre dramaturgy and direction.

Between the end of the 1990s and the first years of the 2000s other theatre courses in the field of social fragility were developed in parallel with the Milan and Turin experiences, notably in Bologna and Urbino. In the University of Bologna, Cristina Valenti, a pupil of Claudio Meldolesi, carries on the reflection on the concept of "theatre of social interaction", in particular in the areas of disability and prison (Valenti, 2004). On these topics the magazine Quaderni di Teatro Carcere - of which Valenti is editor-in-chief was launched in 2014, with the contribution of the University of Bologna. The magazine is part of the wider panorama of the Coordinamento Teatro Carcere Emilia-Romagna (Emilia-Romagna theatre prison coordination), which includes, together with the Emilia-Romagna Regional Authority, several theatre companies with strong background in the field.

The Urbino experience is led by Emilio Pozzi - Chair of History of Theatre and Entertainment at the Faculty of Sociology - co-founder with Vito Minoia of the Aenigma Association. In 1999, Pozzi and Minoia published Di alcuni Teatri delle diversità, where they proposed to:

verify the possibility of acknowledging the specificity of forms of acted theatre, considered until recently marginal, each in its own singularity, and which instead have a solid common denominator: the imprint of diversity (Pozzi and Minoia, 1999, p. 7).

The book is an open and evocative reflection on theatre and its anthropological function in contexts of diversity - such as prison, disability, mental illness, drug addiction -, analysed through papers and interviews with artists and professionals including among others Armando Punzo, Enzo Toma, Donatella Massimilla, Marco Martinelli, Pippo Delbono. This experience led to the foundation of the magazine Teatri delle diversità (theatres of diversities) directed by Minoia himself and of the homonymous conference - in its twentieth edition in 2019 - based first in Cartoceto and then in Urbania. They should be granted the merit of collecting and systematising different national experiences of theatre in contexts of diversity. 
More recent is the birth of the Officine Social Meccaniche di Catania (sociomechanical workshop), a group of social theatre operators who trained in 2010-2011 at the I Vulcanici (the volcanics) advanced training course promoted by the Università Cattolica of Milan and directed by Guglielmo Schininà. The Officine, founded by Luisa Cannella, Maria Giovanna Italia, Maria Chiara Salemi, conduct social theatre activities in the San Berillo district of Catania and host a biennial social theatre event in collaboration with the University of Catania, consisting of shows, debates, workshops and conferences.

The history of social theatre was born in the university context and is placed alongside the hundreds of social theatre groups working throughout the entire nation, with various forms and results. The research work in universities also develops through projects in action always striving for methodological innovation, creating a national ecosystem - with great knowledge transfer and exchange - made up of essays, journals, laboratories, research, evaluation activities and projects in action. This ecosystem of practices and scientific research has resulted in continuous evolution of teaching and training activities. In this case, the university is on the borderline between its role as a place dedicated to higher education and research and what in Italy is known as the "third mission", i.e. the opening of the academy towards civil society with a view to sharing knowledge and assuming a role of reference for the region. In Italy this has enabled social theatre to open a dialogue with local contexts, to consider the differences between practices in the field as an asset and to create networks of professional bodies.

Two recent cases worth mentioning are: the case of the TiPici Network Trasformazione Partecipata della Comunità (Transformation-ParticipationCommunity) - in Milan and that of the Distretto Sociale Barolo ${ }^{49}$ in Turin. The TiPici Network was founded in 2019 by Innocenti Malini, bringing together twenty-one cultural and social organisations that carry out theatre projects in areas of disadvantage in the city of Milan. In the same year in Turin, the Spazio BAC was created and became the permanent seat of the SCT Centre. It is located within the Barolo Social District, a large social system consisting of several buildings and courtyards hosting dozens of third sector associations, with which the Centre develops special projects and collaborative networks with the idea of promoting increasingly deeplyrooted synergies between culture, society and the local environment.

49 The headquarters and the District itself are owned by the Opera Barolo Foundation, which promotes the idea of beauty as a vehicle for the care and well-being of people. 